\title{
Relationships among age, deprivational severity and intake behavior of rats
}

\author{
F. ROBERT TREICHLER AND MARSHA J. HOERNIG \\ KENT STATE UNIVERSITY
}

The effects of different kinds of deprivation were compared in rats of various ages. Sixteen groups of $10 \mathrm{Ss}$ at ages 28, 50,100 , and 200 days were either ad lib maintained or terminally deprived of food, water, or both food and water. Survival measures indicated significant differences in severity as a consequence of age, deprivation regimen, and their interaction. This interaction appeared to depend upon some characteristic intake behaviors of rats. Although food intakes were independent of age, water intake was directly related to age and, thus, constituted a relatively severe deprivation condition for older Ss.

Several comparisons of the severity of food, water, or combined food and water deprivation have yielded different outcomes when rats of different ages have served as Ss. Treichler \& Hall (1962), employing Ss of approximately 100 days, found no differences in weight losses under these three deprivation regimens. However, Treichler \& Feeney (1963) found food deprivation to be more severe than water deprivation for 25 day old Ss in terms of both weight loss and duration of survival. Dufort (1963), using 212 day old Ss, reported that weight levels after 12 days of combined deprivation were lower than those resulting from either food or water deprivation alone and that the individual withdrawals did not have differential consequences.

The present experiment attempted to make direct comparisons of deprivation regimen effects at different age levels by assessing their influence upon survival time and intakes of either food or water by Ss deprived of the other commodity. The purpose of the study was to define the relationship between age and relative severity of different deprivational treatments and to demonstrate that these relationships were based upon intake behaviors at different ages.

Subjects

Four groups of 40 male Holtzman albino rats served as Ss. These groups were comprised of animals at either $28,50,100$, or 200 days of age at the onset of deprivation.

Apparafus

All Ss were individually housed in wire mesh cages and Purina chow and tap water served as the only dietary constituents. Temperature was thermostatically regulated and external windows provided a daynight cycle.

\section{Procedure}

Upon delivery all Ss were given at least $72 \mathrm{hr}$. of unrestricted access to food and water before assignment to deprivation conditions. The $40 \mathrm{Ss}$ within each age group were randomly assigned to one of four treatment groups which received either complete deprivation, food withdrawal, water deprivation, or free food and water access.

Ss were weighed and deprivations were instituted at approximately $11 \mathrm{~A} . \mathrm{M}$. on the first test day. Thereafter, weights were recorded every $12 \mathrm{hr}$. Food spillage was measured and considered in the adjustment of intake measures.

Results

All Ss under deprivation conditions were compared via an analysis of variance of the survival measure and significant differences were observed as a function of age ( $F=234.9, \mathrm{df}=3 / 108, \mathrm{p}<.01)$, type of deprivation $(F=11.8, \mathrm{df}=2 / 108, \mathrm{p}<.01)$, and their interaction $(F=10.2, \mathrm{df}=6 / 108, p<.01)$. The results of subsequent Newman-Keuls comparisons between individual conditions at the .01 level and mean survival durations are displayed in Table 1.

Figures 1 and 2 show mean daily intakes during terminal deprivation of either food or water for Ss in the various age groups. Data are displayed for all days on which five or more Ss survived. Additionally, mean daily intakes of nondeprived control Ss are presented in the legends. Analysis of variance indicated no significant differences among food intakes during deprivation for the various age groups $(F=.46$, df $=3 / 406, p>.05$ ), but significant differences among

Table 1

Relative severity of lood (F), water (W) or combined (C) deprivations at various ages. Mean survival durations are displayed and conditions which do not differ significantly in .01 level Newman-Keuls comparisons are underlined by a common line; conditions not underlined by a common line do differ.

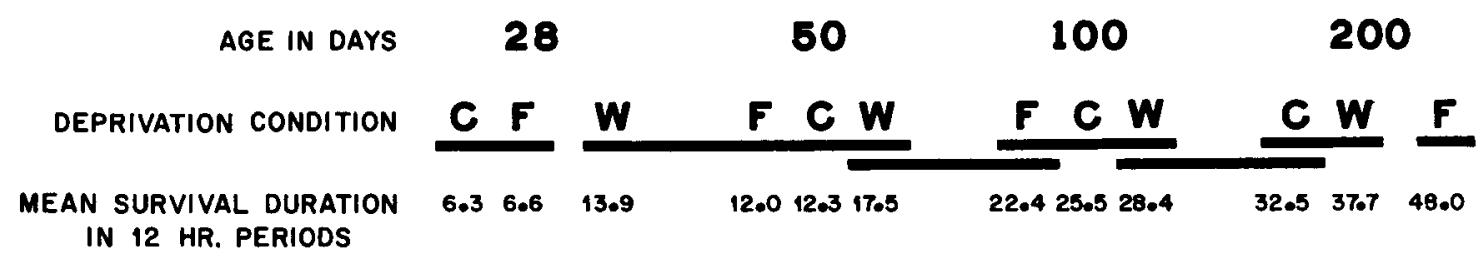

Psychon. Sci., 1967, Vol. 8 (3) 


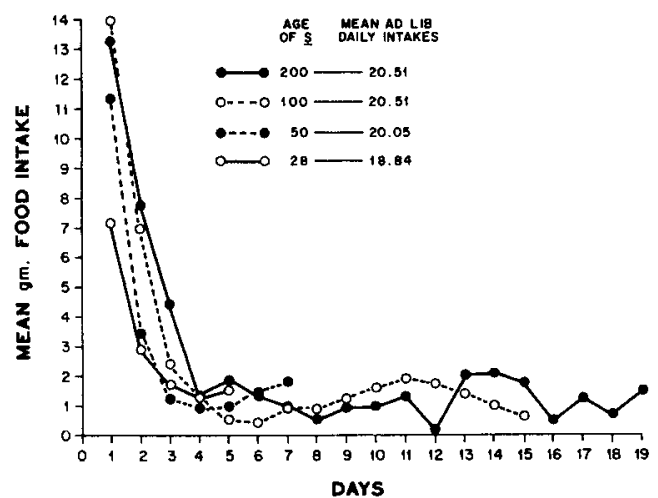

Fig. 1. Mean daily food intake in $g$ for terminally water-deprived rats at various ages. Mean daily intakes for ad lib control Ss of the same ages are indicated in the legend.

water intakes were observed $(F=16.08, \mathrm{df}=3 / 408$, $\mathrm{p}<.01)$. Newman-Keuls comparisons showed that water intakes of 28 and 50 day old Ss were not significantly different at the .01 level. Similarly, the water intakes of 100 and 200 day old Ss did not differ; but both the younger groups did differ from the two older groups. When the intakes of the nondeprived controls were compared, a similar pattern of differences was observed except that the water intakes of 50 and 100 day old Ss did not show reliable differences.

\section{Discussion}

The observed relationships between age and deprivational severity are generally similar to those of other experiments which have surveyed the separate consequences of food (Campbell, Teghtsoonian, \& Williams, 1961) or water (Campbell \& Cicala, 1962) withdrawal. However, the present experiment provides information on both a wider range of ages and an additional type of deprivation regimen.

Severity comparisons at 28 and 100 days old show the same relationships as those obtained in the studies of Treichler \& Feeney (1963) and Treichler \& Hall (1962). However, the results for the 200 day old Ss do not fully agree with Dufort's (1963) comparison

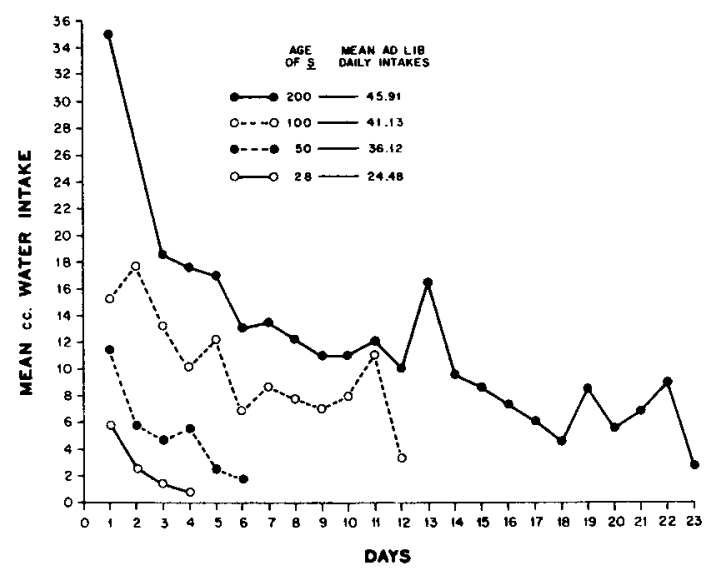

Fig. 2. Mean daily water intake in cc for terminally food-deprived rats at various ages. Mean daily intakes for ad lib control Ss of the same ages are indicated in the legend. of severities in Ss of about this age. It may be recalled that his conclusions were derived from weight measures obtained after 12 days of deprivation, while the present results were based on survival durations. When our Day 12 weights were compared via analyses of variance and subsequent Newman-Keuls tests, they indicated that, as in Dufort's results, combined deprivation was indeed more severe than either of the single withdrawals. However, in contrast to his results, our characteristic indication of significantly greater severity of water than food deprivation was also evident.

One striking feature of the present results is evident in the comparison of intake measures, where it may be noted that Ss of all ages eat nearly identical amounts of dry food under ad lib feeding and similarly reduce their food intakes under water deprivation. Conversely, water intakes under food deprivation or ad lib conditions appear directly related to age and, thus, the weight of an S. In contrast to the conclusions of Siegel \& Stuckey (1947), these results suggest that the large differences in weight provided by Ss of different ages allow the observation of a marked positive relationship between size and water intake under both deprivation and free feeding.

Differential intakes may also provide the basis for the interaction of age and deprivation regimen obtained in our analysis of survival durations. Apparently, for the younger rats, food provides a relatively large part of total daily intake, and its withdrawal constitutes a drastic deprivation. However, since water makes up a larger amount of the 200 day old's intake, water deprivation is comparatively more severe than the withdrawal of food for Ss at this age.

Food or water deprivations have been shown to produce distinctive effects on the stabilimetrically measured activity of rats at different ages (Campbell \& Cicala, 1962). The results of the present study urge that similar investigations which manipulate intakes consider the potential consequences of the interaction of age and deprivation regimen variables.

\section{References}

Campbell, B, A., \& Cicala, G. A. Studies of water deprivation in rats as a function of age. J. comp. physiol. Psychol., 1962, 55, 763-768

Campbell, B. A., Teghtsoonian, R., \& Williams, R. A. Activity weight loss, and survival time of food-deprived rats as a function of age. J. comp. physiol. Psychol., 1961, 54, 216-219.

Dufort, D. H. Weight loss in rats continuously deprived of food, water, and both food and water. Psychol. Rep., 1963, 12, 307312.

Siegel, P. S., \& Stuckey, H. L. An examination of some factors relating to voluntary water intake of the rat. J. comp. physiol. Psychol., 1947, 40, 365-370.

Treichler, F. R., \& Feeney, D. M. Running activity of weanling rats under food or water deprivation. Psychol. Rep., 1965, 16. 906-908

Treichler, F. R., \& Hall, J. F. The relationship between deprivation weight loss and several measures of activity. $J$. comp. physiol. Psychol., 1962, 55, 346-349. 